\title{
Calorimetric and Thermodynamic Studies of Complex Ferrites in the Temperature Range of 298,15-673K
}

\author{
M.M. MATAEV ${ }^{1}$, N.O. MYRZAKHMETOVA², ZH.K. KUANYSHEVA², \\ I.S.SAPARBEKOVA ${ }^{2}$, S.M.BAZILBAYEV ${ }^{2}$, G. A. DOSZHANOVA ${ }^{2}$ and G. MEDEUOVA ${ }^{2}$ \\ ${ }^{2}$ Kazakh State Women's Teacher Training University \\ 'Institute of High Technologies, 99, Aytekebi, Almaty, 050000 \\ 168 Bogenbay Batyra, Almaty, 050012, Kazakhstan. \\ http://dx.doi.org/10.13005/ojc/310153
}

(Received: November 30, 2014; Accepted: January 16, 2015)

\begin{abstract}
By method of dynamic calorimetry, in the temperature range between 298,15 and $673 \mathrm{~K}$, isobaric heat capacity of polycrystalline ferrites $\mathrm{Bi}_{2} \mathrm{CaFe}_{4} \mathrm{O}_{10}, \mathrm{BVMgFe}_{2} \mathrm{O}_{5.5}, \mathrm{BiMgFe}_{4} \mathrm{O}_{10}$ was experimentally studied. Mathematical processing of experimental data made it possible to derive polynomial equation of temperature dependence of ferrites heat capacity for respective temperature ranges, in dependencies $\mathrm{C}^{0} \sim \mathrm{f}(\mathrm{T})$ of ferrite $\mathrm{Bi}_{2} \mathrm{CaFe}_{4} \mathrm{O}_{10}$ a jump was detected in heat capacity at $625 \mathrm{~K}$ associated with phase transitions of type II. The values of the thermodynamic functions $\mathrm{C}^{0}(T), \mathrm{H}^{0}(\mathrm{~T})-\mathrm{H}^{0}(298,15), \mathrm{C}^{0}(T), \mathrm{F}^{\mathrm{hh}}(\mathrm{T})$ have been calculated. Standard values of thermodynamic functions were determined using the method of ion increments. The results obtained broaden thermodynamic data bank for complex inorganic crystalline compounds.
\end{abstract}

Key words: oxides, ferrites, heat capacity, thermodynamic functions, calorimetry.

\section{INTRODUCTION}

Study of physico-chemical properties of ferrites formed $\mathrm{Bi}_{2} \mathrm{O}_{3}-\mathrm{Me}^{\prime \prime} \mathrm{O}-\mathrm{Fe}_{2} \mathrm{O}_{3}$ ( $\mathrm{Me}^{\prime \prime}$ - alkaline earth metals) systems is of certain scientific and practical interest for directed synthesis of compounds with desired properties. Analysis of the published data shows that among ferrites, the most studied ones are orthoferrites $\mathrm{BiFeO} 3$, the so-called multiferroics having both electric polarization and magnetic ordering. In recent years interest to these classes of compounds has significantly increased due to perspective of their use as a working environment in information storage and processing devices. On the basis of the most known multiferroic, new materials with ferroelectric properties of the specific electronic and magnetic structures were searched for. Substituted perovskites based on bismuth ferrite often combine ferromagnetic and weak ferroelectric properties under the dominant anti-ferromagnetic ordering ${ }^{1-6}$. 
The purpose of this work is a calorimetric study of $\mathrm{Bi}_{2} \mathrm{CaFe}_{4} \mathrm{O}_{10}, \mathrm{BVMgFe}_{2} \mathrm{O}_{5,5}, \mathrm{Bi}_{2} \mathrm{MgFe}_{4} \mathrm{O}_{10}$ ferrites. The tested ferrites have been synthesized by solid phase interaction of stoichiometrically matching oxide mixtures $\mathrm{Bi} 2 \mathrm{O} 3$, Fe2O3 of chemically pure grade, and carbonates of alkalineearth metals of essential purity. Formation of equilibrium phases of ferrites was detected by Xray diffraction method and types of their symmetry and lattice constants ${ }^{7,8}$ were identified. It has been determined that ferrites crystallize into a tetragonal and cubic structure with the following lattice cell parameters: $\mathrm{Bi}_{2} \mathrm{CaOFe}_{4} \mathrm{O}_{10}-\mathrm{a}=5.56, \mathrm{C}=8.12 \AA$, $V_{\text {el.cell. }}=251.0 \AA 3, Z=1, \rho_{\text {rent. }}=6.56, \rho_{\text {pikn. }}=6.93 \mathrm{~g} / \mathrm{cm}^{3}$ : BiMgFe2O5,5 - $a=11,1 \AA$ A, $V_{\text {el.cell }}=1382 \AA ̊ 丿 3, Z=8$, $\rho_{\text {rent }}=6,02, \rho_{\text {pikn }}=3,03 \mathrm{~g} / \mathrm{cm}^{3}:$ Bi2MgFe4O10$a=11,1 \AA, V_{\text {el.cell }}=1364 \AA ̊ 3, Z=16, \rho_{\text {rent }}=9,66$, $\rho_{\text {pikn }}=9,60 \mathrm{~g} / \mathrm{cm}^{3}[9]$.

\section{MATERIALS AND METHODS}

Heat capacity of ferrites was investigated by dynamic calorimetry method using a serial device IT-400 in the temperature range between 298 and $673 \mathrm{~K}$. Experiments were performed in the mode of a monotonous close to linear heating of the sample at the average heating rate of about $0.1 \mathrm{~K}$ per second. The maximum error of measurement of specific heat capacity using the IT-400 device according to the datasheet is $\pm 10 \%[10,11]$. Principle of calorimeter operation is based on comparative method of a dynamic c-calorimeter with a heat meter. The tested sample placed in a metal vial of the measuring cell was heated up continuously by heat flow through a calorimeter. After every $25{ }^{\circ} \mathrm{C}$ of heating, time lag of the vial temperature was measured against temperature of the base, using a micro voltamperemeter $-136 \mathrm{~V}$ and a stopwatch SEC-100. The meter had been precalibrated, i.e., thermal conduction of the $\mathrm{K}_{\mathrm{T}}$ calorimeter was defined. After that, specific heat of a standard copper sample was defined, as well as specific and molar heat capacities of the substance. Thermal conductivity of the heat meter was defined by the following formula:

$$
K_{\tau}=\frac{C_{\text {copper.sample }}}{\bar{\tau}_{\text {T.M. }}-\bar{\tau}_{T}^{0}},
$$

where $\mathrm{C}_{\text {copper.sample }}$ is the total heat capacity of a copper sample in $\mathrm{J} / \mathrm{K}, \bar{\tau}_{T, M}$ is the average lag time at the heat meter in experiments with copper sample in seconds, $\bar{\tau}_{T}^{0}$ is the average lag time at the heat meter in experiments with an empty vial.

Table 1: Experimental values of heat capacity

\begin{tabular}{lcc} 
T, K & \multicolumn{2}{c}{$\mathrm{Bi}_{2} \mathrm{CaFe}_{4} \mathrm{O}_{10}$} \\
\cline { 2 - 3 } & $\mathbf{C O p}+\delta(\mathrm{J} / \mathrm{g} \cdot)$ & $\mathrm{COp}+\Delta^{\circ}(\mathrm{J} / \mathrm{mol})$ \\
\hline 298.15 & $0,429 \pm 0,02$ & $360,81 \pm 11,9$ \\
323 & $0,439 \pm 0,01$ & $369,73 \pm 5,86$ \\
348 & $0,450 \pm 0,01$ & $378,92 \pm 5,71$ \\
373 & $0,464 \pm 0,01$ & $390,25 \pm 5,41$ \\
398 & $0,469 \pm 0,01$ & $394,63 \pm 5,48$ \\
423 & $0,486 \pm 0,02$ & $408,71 \pm 10,5$ \\
448 & $0.491 \pm 0.01$ & $412,99 \pm 5,24$ \\
473 & $0,505 \pm 0,02$ & $425,31 \pm 10,1$ \\
498 & $0,512 \pm 0,02$ & $430,45 \pm 10,0$ \\
523 & $0,524 \pm 0,01$ & $441,12 \pm 4,9$ \\
548 & $0,535 \pm 0,02$ & $450,83 \pm 9,61$ \\
573 & $0,544 \pm 0,02$ & $458,06 \pm 9,45$ \\
598 & $0,552 \pm 0,01$ & $464,86 \pm 4,66$ \\
623 & $0,549 \pm 0,01$ & $360,81 \pm 11,9$ \\
648 & $0,557 \pm 0,01$ & $369,73 \pm 5,86$ \\
673 & $0,592 \pm 0,01$ & $378,92 \pm 5,71$ \\
\hline
\end{tabular}

Table 2: Equation of temperature dependence ferrites hear capacity

\begin{tabular}{lcccc}
\hline \multirow{2}{*}{ Compound } & \multicolumn{3}{c}{$\mathbf{C r = a + b T + \mathbf { c T } - 2}$} & \multirow{2}{*}{$\Delta \mathbf{T}, \mathbf{K}$} \\
\cline { 2 - 4 } & $\mathbf{a}$ & $\mathbf{b ~ 1 0 - 3}$ & $\mathbf{c} \cdot \mathbf{1 0}$ & \\
\hline $\mathrm{Bi}_{2} \mathrm{CaFe}_{4} \mathrm{O}_{10}$ & $266,36 \pm 18$ & $334 \pm 0,02$ & $0,293 \pm 0,02$ & $298,15-673$ \\
$\mathrm{BiMgFe}_{2} \mathrm{O}_{5,5}$ & $148,77 \pm 10$ & $198 \pm 0 / 01$ & $0,101 \pm 0,01$ & $298,15-673$ \\
$\mathrm{Bi}_{2} \mathrm{MgFe}_{4} \mathrm{O}_{10}$ & $255,19 \pm 18$ & $403 \pm 0,03$ & $0,565 \pm 0,04$ & $298,15-673$ \\
\hline
\end{tabular}


Table 3: Thermodynamic functions of ferrites in temperature range between 298.15 and $673 \mathrm{~K}$

\begin{tabular}{|c|c|c|c|c|}
\hline $\mathrm{T}, \mathrm{K}$ & $\begin{array}{c}\mathrm{C}_{\mathrm{P}}{ }^{0}(\mathrm{~T}), \mathrm{J} / \mathrm{mol} \mathrm{K} \\
2\end{array}$ & $\begin{array}{r}\mathrm{S}^{0}(\mathrm{~T}) \mathrm{J} / \mathrm{mol} \mathrm{K} \\
3^{\mathrm{Bi}_{2} \mathrm{C}}\end{array}$ & $\begin{array}{l}\mathrm{F}^{\mathrm{hh}}(\mathrm{T}), \mathrm{J} / \mathrm{mol} \mathrm{K} \\
{ }_{4} \mathrm{O}_{10} \\
\end{array}$ & $\begin{array}{c}\mathrm{H}^{0}(\mathrm{~T}) \mathrm{H}^{0}(298.15) \mathrm{kJ} / \mathrm{mol} \\
5\end{array}$ \\
\hline 300 & 206,10 & 413,96 & 269,80 & 413,06 \\
\hline 325 & 216,42 & 423,93 & 3516,63 & 413,11 \\
\hline 350 & 228,07 & 432,52 & 6530,50 & 413,87 \\
\hline 375 & 235,25 & 439,92 & 9311,38 & 415,09 \\
\hline 400 & 237,05 & 446,28 & 11859,24 & 416,63 \\
\hline 425 & 246,41 & 451,71 & 14174,04 & 418,36 \\
\hline 450 & 257,73 & 456,31 & 16255,79 & 420,19 \\
\hline 475 & 268.28 & 460,18 & 18104,46 & 422,07 \\
\hline 500 & 273,67 & 463,38 & 19720,05 & 423,94 \\
\hline 525 & 288,58 & 465,98 & 21102,54 & 425,79 \\
\hline 550 & 290,70 & 468,04 & 22251,93 & 427,58 \\
\hline 575 & 270,19 & 469,59 & 23168,21 & 429,31 \\
\hline 600 & 292,93 & 470,70 & 23851,39 & 430,94 \\
\hline 625 & 302,34 & 471,38 & 24301,47 & 432,49 \\
\hline 650 & 310,86 & 471,67 & 24518,43 & 433,94 \\
\hline 675 & 320,77 & 471,60 & 24502,28 & 435,30 \\
\hline \multicolumn{5}{|c|}{$\mathrm{BiMgFe}_{2} \mathrm{O}_{5.5}$} \\
\hline 300 & 319,63 & 234,39 & 534,82 & 323,62 \\
\hline 325 & 322,36 & 255,49 & 7189,14 & 233,37 \\
\hline 350 & 325,00 & 274.87 & 13786,05 & 235,49 \\
\hline 375 & 327,58 & 292,78 & 20325,53 & 238,59 \\
\hline 400 & 330,10 & 309,41 & 26807,55 & 242,39 \\
\hline 425 & 332,58 & 324,89 & 33232,11 & 246.71 \\
\hline 450 & 335,04 & 339,38 & 39599,21 & 251,38 \\
\hline 475 & 337,48 & 352,96 & 45908,82 & 256,31 \\
\hline 500 & 339,89 & 365,73 & 52160,96 & 261,41 \\
\hline 525 & 342,29 & 377,77 & 58355,62 & 266,62 \\
\hline 550 & 344,67 & 389,15 & 64492,78 & 271,89 \\
\hline 575 & 347,05 & 399,92 & 70572,46 & 277,19 \\
\hline 600 & 349,41 & 410,14 & 76594,65 & 282,49 \\
\hline 625 & 351,76 & 419,85 & 82559,34 & 287,76 \\
\hline 650 & 354,11 & 429,09 & 88466,54 & 292,99 \\
\hline 675 & 356,46 & 437,91 & 94316,24 & 298,18 \\
\hline \multicolumn{5}{|c|}{$\mathrm{Bi}_{2} \mathrm{MgFe}_{4} \mathrm{O}_{10}$} \\
\hline 300 & 275,42 & 222,18 & 169,94 & 221,62 \\
\hline 325 & 283,69 & 228,51 & 2181,83 & 221,80 \\
\hline 350 & 291,92 & 233,78 & 3993,44 & 222,37 \\
\hline 375 & 300,10 & 238,15 & 5604,47 & 223,21 \\
\hline 400 & 308,26 & 241,73 & 7014,90 & 224,20 \\
\hline 425 & 316,39 & 244,61 & 8224,73 & 225,26 \\
\hline 450 & 324,50 & 246,88 & 9233,95 & 226,36 \\
\hline 475 & 332,61 & 248,59 & 10042,56 & 227,45 \\
\hline 500 & 340,70 & 249,81 & 10650,56 & 228,51 \\
\hline 525 & 348,78 & 250,58 & 11057,94 & 229,51 \\
\hline 550 & 356,86 & 250,94 & 11264,70 & 230,46 \\
\hline 575 & 364,93 & 250,93 & 11270,85 & 231,33 \\
\hline 600 & 372,99 & 250,58 & 11076,37 & 232,12 \\
\hline 625 & 381,05 & 249,92 & 10381,28 & 232,83 \\
\hline 650 & 389,10 & 248,97 & 10085,55 & 233,46 \\
\hline 675 & 397,15 & 247,76 & 9289,22 & 233,99 \\
\hline
\end{tabular}


The total heat capacity of the copper sample was calculated according to the following equation:

$$
C_{\text {copper.sample }}=C_{m} \cdot m_{\text {sample }},
$$

where $C_{m}$ is the tabular value of specific heat capacity of copper in $\mathrm{J} /(\mathrm{kg} \cdot \mathrm{K})$, and $\mathrm{M}_{\text {sample }}$ is the mass of the copper sample in $\mathrm{kg}$.

The value of specific heat capacity of the substance tested was calculated by the following formula:

$$
C_{\text {ud. }}=\frac{K_{T}}{m_{0}}\left(\tau_{T}-\tau_{T}^{0}\right),
$$

where $\mathrm{K}_{\mathrm{T}}$ is the thermal conductivity of the heat meter, $\mathrm{mo}$ is the mass of the tested substance in $\mathrm{kg}$, $\mathrm{Tt}$ is the time lag of temperature at the heat meter in seconds, and $\tau_{T}^{0}$ is the time lag of temperature at the heat meter in experiments with an empty vial in seconds.

Five experiments were made for each sample temperature range. The obtained results of the lag time at the heat meter were averaged and processed by methods of mathematical statistics. For the average values of specific heat capacities at each temperature, standard deviations $(\bar{\delta}, \mathrm{J} /$ $(\mathrm{g} \cdot \mathrm{K}))$, average values for molar heat capacities, and random error components $\left(\Delta^{\circ}, \mathrm{J} /(\mathrm{mol} \mathrm{K})\right)$ were calculated $^{10}$.

\section{RESULTSAND DISCUSSION}

Calibration of the instrument was made by measuring standard heat capacity Q-A12O3. The obtained value of $\mathrm{C}_{\mathrm{p}}^{0}(298.15) \mathrm{A} 12 \mathrm{O} 3[76.0 \mathrm{~J} / \mathrm{mol}$ $\mathrm{K}]$ satisfactorily aggrees with the recommended one - $[79.0 \mathrm{~J} / \mathrm{mol} \mathrm{K}]^{11}$.

Table 1 shows results of calorimetric definition of the $\mathrm{BVSaFe}_{4} \mathrm{O}_{10}$ ferrite heat capacities.
In studying the heat capacity of $\mathrm{BiCaFe}_{4} \mathrm{O}_{10}$ ferrite within the limits between $598 \mathrm{~K}$ and $648 \mathrm{~K}$, jumps of value $\mathrm{C}^{\circ} \mathrm{p} \sim \mathrm{f}(\mathrm{T})$ were found, probably related to phase transitions of II kind. These transitions may be caused by cationic rearrangements, changing coefficients of thermal expansion and changes of magnetic moments of synthesized ferrites.

Mathematical processing of experimental data was used to derive equations of temperature dependence of ferrites heat capacity for respective temperature ranges $\Delta \mathrm{T}$ (Table 2$)^{12,13}$.

Due to the fact that specifications of IT- 400 calorimeter do not allow calculation of values of the standard entropy of compounds from experimental data about heat capacity, they were assessed using the system of ion entropy increments ${ }^{14}$. Errors of temperature dependence of the thermodynamic functions were calculated basing on the average error of the heat capacity and accuracy of entropy calculation ( $3 \%)$. Next, by the known relations of the experimental data on $\mathrm{C}_{\mathrm{p}}^{0} \sim \mathrm{f}(\mathrm{T})$ and the calculated values of $\mathrm{S}^{\circ}(298.15)$, the temperature dependencies of the thermodynamic functions $\left.\mathrm{C}_{\mathrm{p}}^{0}(\mathrm{~T}), \mathrm{H}^{0}(\mathrm{~T})-\mathrm{H}^{0} 298.15\right)$, $\mathrm{C}^{0}(\mathrm{~T}), \mathrm{F}^{* \star}(\mathrm{T})$ (Table 3 ) were calculated.-

\section{CONCLUSION}

Thus, for the first time, in the temperature range 298.15 - $673 \mathrm{~K}$, the isobaric heat capacities of $\mathrm{Bi}_{2} \mathrm{CaFe}_{4} \mathrm{O}_{10}, \mathrm{BiMgFe}_{2} \mathrm{O}_{5,5}, \mathrm{Bi}_{2} \mathrm{MgFe}_{4} \mathrm{O}_{10}$ ferrites were experimentally determined. Equations that describe their dependence on temperature have been made. In course of changing the heat capacity of $\mathrm{Bi}_{2} \mathrm{CaFe}_{4} \mathrm{O}_{10}$ at $625 \mathrm{~K}$, heat capacity jumps were discovered, probably related to phase transitions of II kind. Values of thermodynamic functions $\mathrm{C}_{\mathrm{p}}{ }_{\mathrm{p}}(\mathrm{T})$, $H^{0}(T)-H^{0}(298,15), S^{\circ}(T), F^{\text {hh }}(T)$ have been defined. The results obtained increase thermodynamic database about complex inorganic crystalline compounds. 
1. Tokura,Y. and S. Seki,Multiferroics with Spiral Spin Orders. Advanced Materials, 2010, 22: 1554.

2. Ivanov, V.A., T.G.Aminov, V.M.Novogortsev and V.V.Kalinnikov, 2004.Spintronics and spintronic materials. Bulletin of Academy of Sciences. Chemical series, 11: 2255-2303.

3. Valencia, S., Z.Konstantinovic, D. Schmitz, A. Gaupp, L.Balcells and B. Martínez Interfacial effects in manganite thin films with different capping layers of interest for spintronic applications. Physical Review ., 84: 024413.

4. Cheong,S.-W. and M. Mostovoy, Multiferroics: a magnetic twist for ferroelectricity. Nature Materials, 2007, 6: 13.

5. Ramesh, R. and N.A. Spaldin, Multiferroics: progress and prospects in thin films. Nature Materials, 2007, 6: 21.

6. Gavrilova, L.Y., T.V.Aksenov and V.A.Cherepanova, Phase equilibriums and crystalline structure of complex oxides in Ln$\mathrm{M}-\mathrm{Fe}-\mathrm{O}$ (M-Ca, Sr) system. Inorganic Chemistry Journal, 2008, 53(6): 1027-1033.

7. Aldabergenov, M.K., M.M.Mataev and A.T.Baibosynova, Calculation of manganates formation enthalpies and Gibbs energies. Bulletin of the Eurasian University, 2000, 1: 136-140.

8. Kasenov, B.K., A.T.Oralova, B.Z.Nurgaliyev and M.M.Mataev, Thermodynamic functions of LnBaMn2O5, 5 (Ln-La, Nd, Gd, Ho, Er, $\mathrm{Lu}$ ) in the range between 298.15 and $673 \mathrm{~K}$. Journal of Physical Chemistry, 1996, 70(5): 944-947.
9. M.M. Mataev, N.O.Myrzahmetova, N.A.Zhumanova, Zh.K. Kuanysheva, M.A. Nurbekova and M.R.Abdraimova, Synthesis and X-Ray Scattering Analysis of Complex Manganites and Ferrites. World Applied Sciences Journal, 2013, 21(7): 1032-1035.

10. Mataev, M.M., N.O.Myrzahmetova, D.Zh. Nuketaeva, A.Zhumanova, Zh.K. Kuanysheva, M.A.Nurbekova and M.R. Abdraimova, Heat Capacity and Thermodynamic Functions of Complex Manganites and Ferrites in Temperature Range 298.15 - 673K. Middle East Journal of Scientific Research (MEJSR), 2013, 4(1): 5-8.

11. Platunov, E.S., S.E.Buravoy, V.V.Kurepin and G.S.Petrov, Thermophysical measurements and instruments. Leningrad: Mechanic Engineering, 1986, 256.

12. Spiridonov, V.P. and L.V.Lopatkin, Mathematical processing of experimental data. Moscow: Publishing House of the Moscow State University, 1970, 221.

13. Robie,R.A., .S.Hewingway and J. Fisher, ThermodynamicProperties of Minerals and Related Substances at 298,15 and (105 Paskals) Pressure and at Higher Temperatures. Washington: United States Government Printing Office, 1978, 456.

14. Kumok, V.P., The problem of matching methods for assessing thermodynamic characteristics. Direct and reverse problems of chemical thermodynamics. Novosibirsk: publishing SCIENCE., 1987, 108. 